\title{
Nuclear localization of phosphorylated c-Myc protein in human tumor cells.
}

\author{
C. Soldani ${ }^{1}$, M.G. Bottone ${ }^{1}$, M. Biggiogera ${ }^{1,3}$, C. Alpini², A.I. Scovassi ${ }^{3}$, T. Martin ${ }^{4}$, and C. Pellicciari ${ }^{1,3}$
}

'Dipartimento di Biologia Animale, Università di Pavia, Piazza Botta 10; ${ }^{2}$ Laboratorio di Analisi BiochimicoCliniche, IRCCS San Matteo, Piazzale Golgi 1; ${ }^{3}$ Istituto di Genetica Molecolare del CNR, Via Abbiategrasso 207, Pavia, Italy and ${ }^{4}$ Department of Molecular Genetics and Cell Biology, University of Chicago, USA

Accepted: 7/10/2002

Key words: c-Myc, fibrillarin, fluorescence microscopy, immunocytochemistry, nuclear bodies, nucleolus

\section{SUMMARY}

Using immunocytochemical techniques at light and electron microscopy, we analysed the distribution of phosphorylated c-Myc in actively proliferating human HeLa cells. The distribution pattern of c-Myc was also compared with those of other ribonucleoprotein (RNP)-containing components (PANA, hnRNP-core proteins, fibrillarin) or RNP-associated nuclear proteins (SC-35 splicing factor). Our results provide the first evidence that phosphorylated c-Myc accumulates in the nucleus of tumor cells, where it colocalizes with fibrillarin, both in the nucleolus and in extranucleolar structures.

\section{INTRODUCTION}

The proto-oncogene c-myc encodes a phosphoprotein which plays a crucial role both in driving cell proliferation and in promoting apoptosis; these opposite roles are likely mediated by its interaction with specific molecular partners (Amati et al. 2001; Nasi et al., 2001). Deregulated expression of $c-m y c$ contributes to tumorigenesis (Lutz et al., 2002).

In interphase resting cells, c-Myc protein shows a predominant localization in the cytoplasm (where its
$\mathrm{N}$-terminal domain binds to $\alpha$-tubulin: Alexandrova et al., 1995), whereas in proliferating cells its nuclear distribution was reported to overlap with that of some ribonucleoprotein (RNP)-containing structures (Spector et al., 1987), or to accumulate in large amorphous nuclear globules (Henriksson et al., 1988; Koskinen et al., 1991). It has been reported that the release of c-Myc from $\alpha$-tubulin during mitosis is regulated by the c-Myc phosphorylation state (Noguchi et al., 1999; Gregory and Hann, 2000; Niklinski et al., 2000). In fact, c-Myc is highly unstable (half-life of 15-30 minutes) and it is proteolytically degraded via the ubiquitination pathway (Flinn et al., 1998). Despite intensive research, no conclusive evidence has so far been reported on the precise intracellular localization of c-Myc in tumor cells, where its degradation is deregulated with a resulting abnormal stability of c-Myc protein in the nucleus (Flinn et al., 1998; Salghetti et al., 1999; Gregory and Hann, 2000; Niklinski et al., 2000).

In the present investigation, we have analysed by light and electron microscopy the distribution of cMyc in human HeLa cells which have been selected as they are actively proliferating tumor cells and contain a high copy number of the $c-m y c$ gene. We focused on the phosphorylated form of c-Myc since phosphorylation is required for cell proliferation. 
We provide the first evidence that phosphorylated cMyc (P-c-Myc) in fact accumulates in the nucleus of tumor cells, where it colocalizes with fibrillarin, both in the nucleolus and in extranucleolar structures.

\section{MATERIALS AND METHODS}

HeLa cells were grown either in flasks or on glass coverslips in Petri dishes using D-MEM Medium, containing $10 \%$ fetal bovine serum, $2 \mathrm{mM}$ glutamine and 100 units each of streptomycin and penicillin (Celbio, Italy). The cells were maintained at $37^{\circ} \mathrm{C}$ in a humidified atmosphere containing $5 \% \mathrm{CO}_{2}$ and harvested $24 \mathrm{~h}$ after seeding, when they were actively proliferating. For fluorescence microscopy, cells on coverslips were fixed with either $70 \%$ cold ethanol or $4 \%$ formaldehyde in PBS.

Cells were then immunolabeled for P-c-Myc or for different RNPs or RNP-associated nuclear proteins, as follows:

P-c-Myc protein: anti-P-c-Myc (Cell Signaling Technology, Celbio, Italy) diluted 1:100, and an incubation with Alexa 488-conjugated goat antirabbit-IgG (Space Import-Export, Italy);

Proliferation Associated Nuclear Antigen (PANA, locating in the interchromatin granules: Clevenger $e t$ al., 1987): undiluted anti-PANA (ICN Pharmaceuticals, Italy), and incubation with Alexa 488-conjugated goat anti-mouse $\mathrm{IgG}$;

hnRNP core proteins: iD2 antibody (Martin and Okamura, 1981; culture supernatant, diluted 1:2), and incubation with a rabbit anti-mouse IgM, and with Alexa 488-conjugated goat anti-rabbit-IgG; splicing-factor SC-35: anti SC-35 antibody (SignaAldrich, Italy), diluted 1:200 and incubation with Alexa 488-conjugated goat anti-mouse IgG.

nucleolar protein, fibrillarin: human autoimmune serum (diluted 1:500) and incubation with Alexa 594-conjugated goat-anti-human-IgG.

All the incubations were performed at room temperature for $1 \mathrm{~h}$ and cells were finally counterstained for DNA with $0.1 \mu \mathrm{g} / \mathrm{ml}$ of Hoechst 33258 for $10 \mathrm{~min}$, and mounted in a drop of Mowiol (Calbiochem, Inalco, Italy).

Micrographs were taken with an Olympus Camedia C-2000 Z mounted on an Olympus BX50 fluorescence microscope.

For electron microscopy (EM), the cells were trypsinized, fixed with $4 \%$ paraformaldehyde in DMEM at $4^{\circ} \mathrm{C}$ for $2 \mathrm{~h}$ and rinsed in phosphate buffer $(\mathrm{pH}$ 7.2). The specimens were then embedded in LR
White resin, as reported in Pellicciari et al. (2000). Ultrathin sections on formvar-carbon-coated nickel grids were incubated on a drop of normal goat serum (NGS) diluted 1:100 in PBS for $3 \mathrm{~min}$. The incubation with the the anti-P-c-Myc polyclonal antibody, diluted 1:20 in PBS-0.05\% Tween-0.1\% BSA was performed at $4^{\circ} \mathrm{C}$ for $17 \mathrm{~h}$. The grids were then incubated with NGS as above, and for 30 min at room temperature with a goat-anti rabbit IgG (Jackson Immuno Research Lab. Inc., USA) coupled with $12 \mathrm{~nm}$ colloidal gold and diluted 1:20 in PBS. As a control, some grids were floated on the incubation mixture without the primary antibody, treated as above and incubated with the appropriate secondary antibody. All the grids were stained with the EDTA regressive technique of Bernhard (1969) for RNPcontaining nuclear components.

\section{RESULTS AND DISCUSSION}

In Fig. 1a-c, the immunolabeling is shown for two nuclear RNP proteins (PANA and hnRNP core proteins) and the RNP-associated splicing factor, SC35. The labeling patterns are highly characteristic, and they are not morphologically reminiscent of Pc-Myc distribution (Fig. 1d). The simultaneous immunolabeling of P-c-Myc and fibrillarin (Fig. 1eg) confirmed that, in fluorescence microscopy, the two proteins colocalize in nucleoli; some nuclear bodies, definitely smaller than nucleoli, were also positive for both proteins.

At EM, the immunogold labeling for P-c-Myc was especially evident on the dense fibrillar component (DFC) of nucleoli (Fig. 1i). The positivity for P-cMyc on the DFC was also observed in segregated nucleoli (Fig. 1j) after treatment with actinomycin $\mathrm{D}$, which is known to inhibit RNA polymerase I and to induce nucleolar segregation.

In addition, amorphous nuclear bodies and, to a lesser extent, the coiled bodies (CB: fig. 1k) were also positive for $\mathrm{P}-\mathrm{c}-\mathrm{Myc}$ (it is also known that $\mathrm{CBs}$ contain fibrillarin). A weak positivity was also observed at the periphery of the interchromatin granules.

Remarkably, no labeling for P-c-Myc was ever found in the cytoplasm.

We provide here the first evidence in situ of the accumulation of P-c-Myc protein in the nucleus of human tumor cells harboring a high copy number of c-myc gene.

P-c-Myc mostly localizes in the DFC of nucleoli: in fact, the nucleolus contains -besides rRNA pre- 

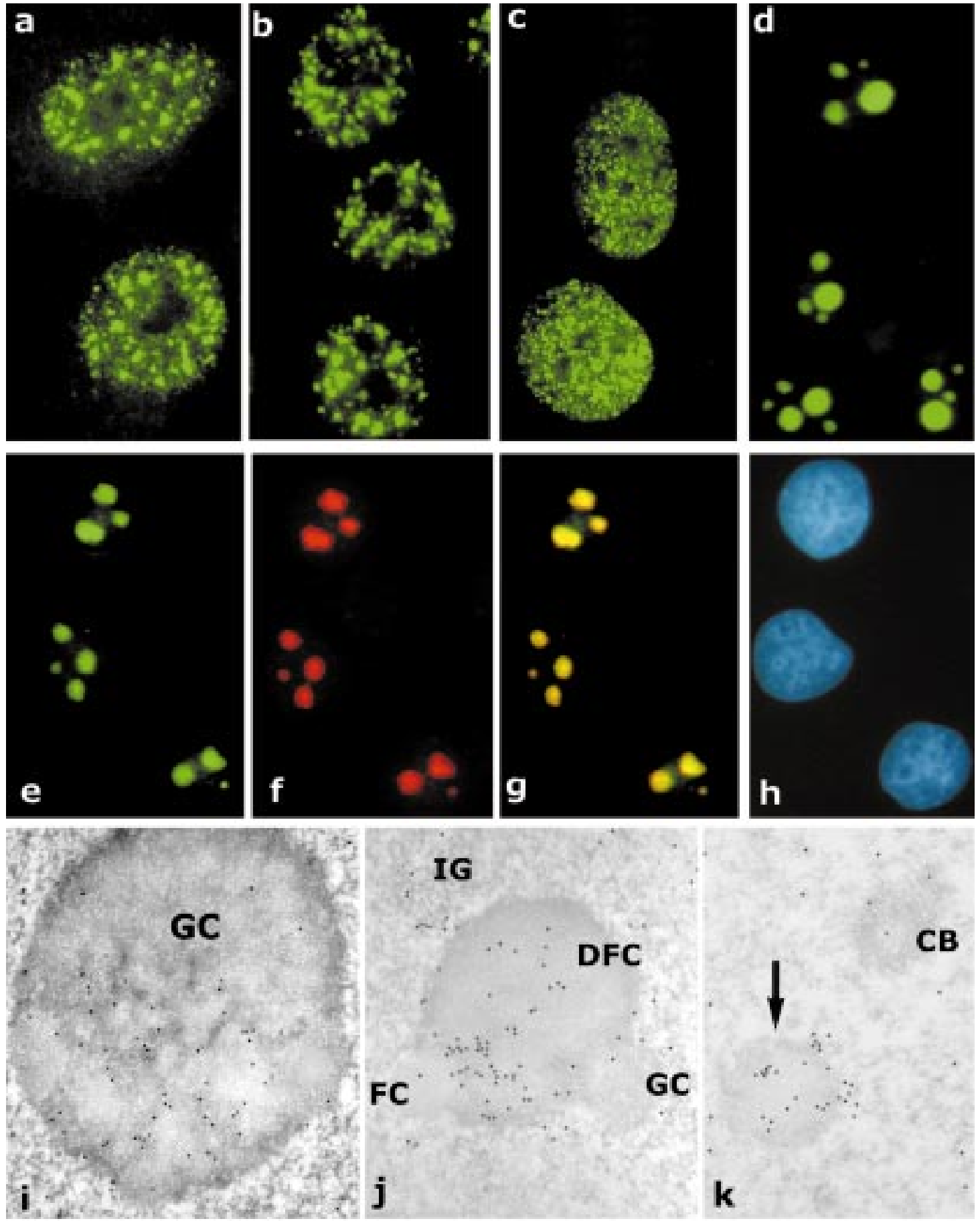

Fig. 1 - Fluorescence and EM immunolabeling of nuclear proteins in HeLa cells. Upper row: Fluorescence immunolabeling for PANA (a), SC-35 (b), hrRNP core proteins (c) and P-c-Myc (d) (x100 objective lens). Middle row: tri-color fluorescence staining for P-c-Myc (e), fibrillarin (f) and DNA (h); the merged image (g) demonstrates that P-c-Myc and fibrillarin colocalize (x63 objective lens). Lower row: EM immunolabeling of P-c-Myc; i) in a nucleolus of a HeLa cell, gold grains are present over the DFC, whereas no labeling is observed over the granular component (GC; $\mathrm{x} 40,000)$; $\mathrm{j}$ ) over a segregated nucleolus (after treatment with $0.1 \mathrm{mg} / \mathrm{ml}$ of actinomycin D for $12 \mathrm{~h}$ ) only the DFC is labeled, the GC and the fibrillar center (FC) being unlabeled; weak immunolabeling is also found at the periphery of intercromatin granules (IG; x60,000); $\mathrm{k}$ ) in untreated HeLa cells, P-cMyc labeling is also found over amorphous nuclear bodies (arrow); coiled bodies (CB) are also weakly labeled (x60,000). 
cursors and small nucleolar RNAs- a large number of protein species (Medina et al., 2000), more than $20 \%$ of which are nucleic-acid-binding proteins (Andersen et al., 2002). When present in the nucleus of actively transcribing cells, such as HeLa, the transcription factor c-Myc may be expected to localize in the nucleolus too; however, as we already mentioned, c-Myc degradation is impaired in tumor cells, and it is likely that P-c-Myc is simply stored in the nucleolus as well as in other nuclear bodies, such as the CB (which is a well known storage and shuttling site for a wide spectrum of nuclear protein: Malatesta et al., 1994; Lam et al., 2002). As for amorphous nuclear bodies, their heterogeneity in composition and function is well documented (Bloch et al., 1999) and their role in storage and/or transport of P-c-Myc is not unlikely.

The hypothesis of an accumulation of P-c-Myc in the nucleolus of tumor cells is strengthened by the evidence that the immunolabeling persists also in the DFC of segregated nucleoli, after inhibiting transcription with actinomycin D.

\section{ACKNOWLEDGEMENTS}

This work was partially supported by the University of Pavia (Fondo di Ateneo per la Ricerca, 2001). Thanks are due to Mrs. Paola Veneroni for her excellent technical assistance.

\section{REFERENCES}

Alexandrova N., Niklinski J., Bliskovsky V., Otterson G.A., Blake M., Kaye F.J., and Zajac-Kaye M.: The N-terminal domain of c-Myc associates with $\alpha$-tubulin and microtubules in vivo and in vitro. Mol. Cell. Biol. 15, 5188-5195, 1995.

Amati B., Frank S.R., Donjerkovic D., and Taubert S.: Function of the c-myc oncoprotein in chromatin remodeling and transcription. Biochim. Biophys. Acta 1471, M135-M145, 2001.

Andersen J.S., Lyon C.E., Fox A.H., Leung A.K.L., Lam Y.W., Steen H., Mann M., and Lamond A.I.: Directed proteomic analysis of the human nucleolus. Curr. Biol. 12, 1-11, 2002.

Bernhard W.: A new staining procedure for electron microscopical cytology. J. Ultrastruct. Res. 27, 250-265, 1969.

Bloch D.L., Chiche J-D., Orth D., De la Monte S., Rosenzweig, A., and Bloch K.D.: Structural and functional heterogeneity of nuclear bodies. Mol. Biol. Cell 19, 4423-4430, 1999.

Clevenger C.V., Epstein A.L., and Bauer K.D.: Modulation of the nuclear antigen p105 as a function of cell-cycle progression. J. Cell Physiol. 130, 336-343, 1987.
Flinn E.M., Busch C.M., and Wright A.P.: myc boxes, which are conserved in myc family proteins, are signals for protein degradation via the proteasome. Mol. Cell. Biol. 18, 59615969, 1998 .

Gregory M.A., and Hann S.R.: c-Myc proteolysis by the ubiquitin-proteasome pathway: stabilization of c-Myc in Burkitt's lymphoma cells. Mol. Cell. Biol. 20, 2423-2435, 2000.

Henriksson M., Klasson M., Ingvarsson S., Koskinen P., Sumegi J., Klein G., and Thyberg J.: Elevated expression of c-myc and N-myc produces distinct changes in nuclear fine structure and chromatin organization. Oncogene 3, 597-593, 1988.

Koskinen P.J., Sistonen L., Evan G., Morimoto R., and Alitalo K.: Nuclear colocalization of cellular and viral myc proteins with HSP70 in myc-overexpressing cells. J. Virol. 65, 842-851, 1991

Lam Y.W., Lyon C.E., and Lamond A.I.: Large-scale isolation of Cajal Bodies from HeLa cells. Mol. Biol. Cell 13, 2461 2473, 2002.

Lutz W., Leon J., and Eilers M.: Contributions of Myc to tumorigenesis. Biochim Biophys Acta, 1602, 61-71, 2002.

Malatesta M., Zancanaro C., Martin T.E, Chan E.K.L., Amalric F., Lührmann R., Vogel P., and Fakan S.: Is the coiled body involved in nucleolar functions? Exp Cell Res. 211, 415-419, 1994

Martin T.E., and Okamura C.S.: Immunocytochemistry of nuclear hnRNP complexes. In: Busch H. (ed) The Cell Nucleus, Vol. 9, Academic Press, New York, pp. 119-144, 1981

Medina F.J., Cerdido A., and de Carcer G.: The functional organization of the nucleolus in proliferating plant cells. Eur. J. Histochem. 44, 117-131, 2000.

Nasi S., Ciarapica R., Jucker R., Rosati J., and Soucek L.: Making decision through Myc. FEBS Lett. 490, 153-162, 2001.

Niklinski J., Claassen G., Meyers C., Gregory M.A., Allegra C.J., Kaye F.J., Hann S.R., and Zajac-Kaye M.: Disruption of Myc-tubulin interaction by hyperphosphorylation of c-Myc during mitosis or by constitutive hyperphosphorylation of mutant c-Myc in Burkitt's lymphoma. Mol. Cell. Biol. 20, 5276-5284, 2000

Noguchi K., Kitanaka C., Yamana H., Kokubu A., Mochizuki T., and Kuchino Y.: Regulation of c-Myc through phosphorylation at Ser-62 and Ser-71 by c-Jun N-terminal kinase. J. Biol. Chem. 274, 32580-32587, 1999.

Pellicciari C., Bottone M.G., Scovassi A.I., Martin T.E., and Biggiogera M.: Rearrangement of nuclear ribonucleoproteins and extrusion of nucleolus-like bodies during apoptosis induced by hypertonic stress. Eur. J. Histochem. 44, 247-254, 2000.

Salghetti S.E., Kim S.Y., and Tansey W.P.: Destruction of Myc by ubiquitin-mediated proteolysis: cancer-associated and transforming mutations stabilize Myc. EMBO J. 18, 717-726, 1999

Spector D.L., Watt R.A., and Sullivan N.F.: The v- and c-myc oncogene proteins colocalize in situ with small nuclear ribonucleoprotein particles. Oncogene 1, 5-12, 1987. 